\title{
ESBOÇOS DE UMA TRAJETÓRIA: CIDADE, PESQUISA, UNIVERSIDADE ${ }^{1}$
}

Heitor Frúgoli Jr. ${ }^{2}$

Minha opção pelas Ciências Sociais não foi uma decisão fácil, tendo em vista o contexto - mais imediato ou mais amplo - em que me encontrava ao final do colegial, em meados da década de 1970. Sempre apreciara as disciplinas ligadas às humanidades, mas havia uma certa pressão social e também familiar para engajar-me ou na engenharia ou na medicina, já que a terceira possibilidade do famoso "tripé" da época, o direito, encontrava-se então saturada no mercado de trabalho. Uma atmosfera difícil, marcada pela ditadura militar e pelo autoritarismo, somada à falta de opções culturais - nasci em São Paulo e vivi até os 10 anos na Vila Prudente, na Zona Leste, e residia então, com minha família, em Mogi das Cruzes, na Grande São Paulo - não favorecia maiores questionamentos.

Paralelamente, quase ao final daquela década, configurava-se um contexto sociocultural e político mais estimulante, com ampliação das liberdades democráticas, ressurgimento dos movimentos sociais e operário, retomada do movimento estudantil, somados à efervescência expressa nos shows de música popular, no teatro, no cinema. Tudo isso se dava num momento em que eu retomava gradativamente minha relação com a cidade de São Paulo ${ }^{3}$, cuja atmosfera eu desejava, de alguma forma, tomar parte. Pude assim adquirir, dentro dos limites da minha condição de juventude, uma consciência mais clara em termos sociais e existenciais, a partir do contato com uma realidade nova e instigante. Foi possível, desse modo, amadurecer um projeto de atuar de uma forma mais engajada e profissional na sociedade, levando-me, após opções anteriores interrompidas, a prestar vestibular em Ciências Sociais na Universidade de São Paulo.

Sobreveio, na faculdade, um aprofundamento nos estudos, para uma compreensão mais sistemática da realidade social. Tive nesse sentido a oportunidade de freqüentar muitas disciplinas cuja formação foi de inestimável valor até hoje,

\footnotetext{
${ }^{1}$ Agradeço a Cornelia Eckert pelo convite para participar do II Colóquio "Individualismo, Sociedade, Memória" (dez./2010, PPGAS/IFCH/UFRGS) e escrever o presente artigo.

${ }^{2}$ Universidade de São Paulo, Brasil.

${ }^{3}$ Que adquiria então um forte significado de metrópole cultural. Sobre o conceito e para uma abordagem sobre os anos 1950 (mais recuados com relação à presente abordagem), ver Arruda (2001).
} 
percorrendo os autores clássicos, as principais vertentes teóricas, além de vários debates contemporâneos. Pode-se dizer, por ocasião da escolha das matérias optativas, que minha formação enveredou a princípio pela sociologia, com um interesse posterior mais flagrante pela antropologia.

Minha primeira pesquisa ${ }^{4}$ mais sistemática ocorreu a partir dos meados do quarto ano da graduação, logo após a participação no curso de Sociologia Urbana, ministrado por Eva Blay, que me incentivou a realizar uma espécie de levantamento etnográfico dos grupos sociais que então utilizavam o Largo da Concórdia ${ }^{5}$ - marreteiros (camelôs), engraxates, desempregados, prostitutas, mendigos (população de rua), dentre outros, a maioria de origem nordestina - buscando analisar estratégias sociais de múltiplas atividades nas ruas, que subvertiam os usos do espaço esperados pelo planejamento urbano.

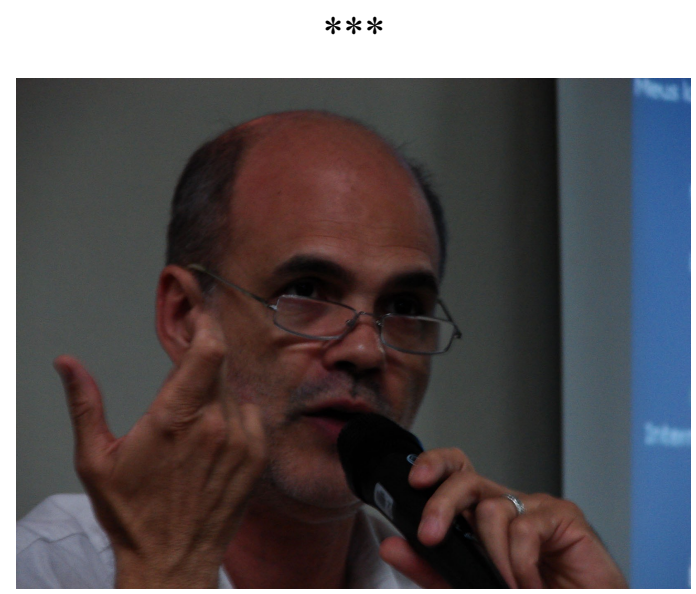

Heitor Frúgoli Jr. Foto de 02 dezembro 2010. II Colóquio Individualismo, Sociabilidade e Memória. Acervo BIEV PPGAS IFCH UFRGS.

Tal trabalho - que se tornou um projeto de iniciação científica ${ }^{6}$ - possibilitou-me adentrar o universo da pesquisa etnográfica, com o duro aprendizado nascido do contato "em carne-e-osso" com os sujeitos abordados: logo no primeiro dia de campo, ocorrera um "rapa" - apreensão das mercadorias dos camelôs pelos fiscais da prefeitura, sob proteção policial e cobertura da grande imprensa, com o protesto dos atingidos e acusações de favorecimento àqueles que pagavam propinas. Dada a densidade do

\footnotetext{
${ }^{4}$ Os projetos no Brasil citados ao longo do texto contaram, em diferentes fases, com auxílios da FAPESP e do $\mathrm{CNPq}$, com exceção daqueles nos quais outras fontes são especificadas.

${ }^{5}$ No histórico bairro do Brás - marcado por sucessivas levas de imigrantes.

${ }^{6}$ Entre 1983 e 1984.
} 
"drama social"7 que se desenvolvia à minha frente, procurava observar tudo, perguntando afoitamente sobre o que ocorria, sem me identificar e fazendo minhas anotações, quando fui rispidamente abordado por camelôs que me tomaram por um "fiscal disfarçado". Desde então aprendi que a sensação de "invisibilidade" do pesquisador, tão comum entre principiantes, é um dos maiores equívocos que se pode cometer numa pesquisa.

O trabalho de campo propriamente dito possibilitou-me captar uma ordem e uma regularidade sob a aparência caótica da ocupação das ruas, embora, olhando retrospectivamente, tenha-me então faltado um melhor preparo teórico para transformar tais dados numa interpretação mais densa. De toda forma, foi possível mais tarde (Frúgoli Jr., 1995) analisar sobretudo determinadas regras e hierarquias presentes no desempenho do trabalho informal nas ruas, a maioria delas invisíveis aos transeuntes, bem como a construção de determinadas estigmatizações ${ }^{8}$. De qualquer modo, entendo que tais dificuldades fazem parte do espírito da iniciação na pesquisa, onde se pode testar os potenciais, bem como perceber lacunas a serem enfrentadas posteriormente.

Foi já na fase final do curso de graduação que tive minha primeira experiência profissional, fora do ambiente acadêmico, como pesquisador numa Assessoria Técnica de Gabinete da Secretaria das Finanças do Município de São Paulo. Tal experiência pontual, de dois anos, possibilitou-me vivenciar certos meandros da dinâmica de trabalho de uma instituição pública. Mais habituado ao ambiente universitário - onde as atividades de pesquisa envolvem geralmente leitura, discussões, avaliações conjuntas dos resultados e das dificuldades - deparei com uma lógica certamente distinta.

Durante meses fiz parte de uma equipe que visitou inúmeras favelas e outras áreas com habitações precárias na periferia de São Paulo, para determinados levantamentos. Ao longo desse trabalho, reelaborei muitos dos estereótipos que tinha sobre esses locais, nos quais fomos sempre muito bem recebidos. Naquela época, tratava-se de espaços, à luz do dia, predominantemente femininos. Obviamente as favelas não eram ainda áreas dominadas territorialmente pelo tráfico de drogas, tal como se dá em muitas hoje em dia. O contato diário e por meses com tais lugares permitiu-me começar a reconhecer uma grande heterogeneidade interna, a começar pelos seus distintos graus de precariedade. Apesar de todos os limites, tal experiência

\footnotetext{
${ }^{7}$ No sentido definido por Turner (2008 [1974]).

${ }^{8}$ Retomarei adiante mais aspectos dessa publicação.
} 
permitiu-me redimensionar a visão que tinha sobre a metrópole ${ }^{9}$, sobretudo quanto à enorme dimensão e amplitude de sua área periférica, bastante desatendida, que na época já constituía um dos focos privilegiados de estudos antropológicos e sociológicos ${ }^{10}$. Arrependo-me de não ter-me ocorrido escrever uma espécie de "diário de campo" dessa experiência - tenho registros muito esparsos -, o que poderia ter sido mais frutífero posteriormente, embora isso tenha me impactado significativamente. Finalizando, tal experiência no serviço público - com projetos sigilosos e decisões sobre os desdobramentos inacessíveis - reafirmou meu desejo de trabalhar, de preferência, no ambiente acadêmico, onde percebia uma maior vocação.

Ao final da minha graduação, firmara-se a intenção de continuar decifrando a cidade principalmente a partir do olhar sobre suas ruas e espaços públicos, mas intrigava-me então o fenômeno do crescimento dos shopping centers, cuja presença na paisagem urbana paulistana passava a chamar atenção, vendo-os a princípio como espécies de "simulacros urbanos" que atraíam um grande número de freqüentadores, à primeira vista especialmente as camadas médias e altas - antes que eu constatasse um crescente uso também pelas camadas populares - concomitante ao esvaziamento e deterioração dos equipamentos de muitas praças, sobretudo nas áreas mais centrais de São Paulo ${ }^{11}$.

Por outro lado, sentia necessidade de referenciais que me levaram a um grande interesse pela antropologia urbana. Assim, concorri e entrei no mestrado em Antropologia Social da Universidade de São Paulo e, sob a orientação de José Guilherme Magnani, estabeleci um contato mais sistemático com a bibliografia clássica e contemporânea da antropologia. Posteriormente, empreendi uma pesquisa para investigar a amplitude sociocultural da apropriação dos shopping centers de São Paulo por múltiplos grupos de usuários, principalmente redes de jovens, que praticam diversas formas de sociabilidade nesses espaços, na articulação entre os campos do lazer e do consumo.

Realizei então um trabalho de campo em três shoppings de São Paulo Iguatemi, Norte e Morumbi - para, através de observações sistemáticas e numa

\footnotetext{
${ }^{9} \mathrm{O}$ que denota um amadurecimento propiciado por uma experiência extra-acadêmica, lembrando que as mesmas são, hoje em dia, tão desvalorizadas pelas agências de fomento à pesquisa.

${ }^{10}$ Para citar apenas uma referência importante, Cardoso (1986).

${ }^{11}$ Olhar esse que eu passara a desenvolver a partir da pesquisa já mencionada sobre o Largo da Concórdia (Brás, São Paulo).
} 
perspectiva comparativa, captar as formas de apropriação desses locais, com especial atenção à dimensão do lazer (Frúgoli Jr., 1992). Para evitar tomar os shoppings como “isolados empíricos", busquei estabelecer nexos comparativos desses estabelecimentos com outros espaços comerciais da cidade $^{12}$. Procurei também atentar, tal como a metáfora de uma peça de teatro, ao "cenário", aos "atores sociais" predominantes e às regras subjacentes às suas relações, tal como um "script" interpretado que prevê múltiplas variações.

Percebo retrospectivamente que sempre tive um particular interesse em tentar investigar novos objetos de pesquisa, tal como se dera nesse caso, com razoável receptividade no campo acadêmico, já que a investigação tocava em aspectos ligados a certas mudanças sociais em curso no uso dos espaços urbanos, a formas de sociabilidade articuladas ao consumo e ao lazer, e ao início de um processo de

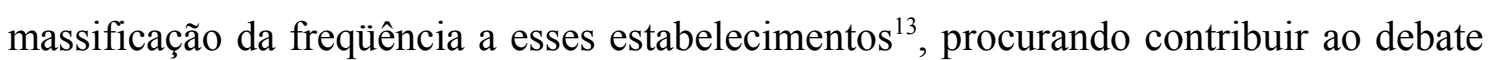
sobre significados e sentidos da modernidade urbana. Obviamente tive que lidar com a falta de uma interlocução mais clara em termos de pesquisas já realizadas, além de enfrentar, ainda que em raras situações, a posição dos que consideravam o objeto "pouco legítimo" dentro das ciências sociais, voltadas tradicionalmente ao estudo dos grupos sociais marginalizados ${ }^{14}$.

Tal pesquisa viabilizou o início de minha participação em vários fóruns de discussão, como encontros da ANPOCS, ABA, CERU, CEBRAP, além de palestras em faculdades, órgãos públicos e escolas, com a ampliação das interlocuções.

Durante a pesquisa para o mestrado, parte do isolamento inerente ao trabalho de confecção da dissertação foi atenuado pela minha participação no então nascente Núcleo de Antropologia Urbana (NAU), do Departamento de Antropologia da USP, coordenado também por José Guilherme Magnani, cujo projeto inicial - "Pedaços e trajetos: formas de lazer e sociabilidade na metrópole" - propiciou-me aprofundar o enfoque em temáticas que já constituíam meu interesse. Isso ensejou que pudéssemos abraçar uma prática coletiva e compartilhada, na qual as descobertas, assim como as

\footnotetext{
${ }^{12}$ Um exercício interessante foi observar, na época e mesmo depois, as formas de ocupação de galerias do centro de São Paulo (ver Frúgoli Jr., 1995, 63-69; ver também Macedo, 2007).

13 Ainda que a representação social predominante ainda hoje os veja como espaços destinados principalmente às classes de maior poder aquisitivo.

${ }^{14}$ Ainda não havia se desenvolvido propriamente uma antropologia do consumo, que a obra de Douglas e Isherwood (2004 [1979]) auxiliou consideravelmente. Retomei a temática mais adiante (Frúgoli Jr., 2008a), com base em eventos ocorridos em alguns shoppings; ver também, a respeito, Puccinelli (2011), sobre pesquisa de iniciação científica por mim orientada.
} 
dificuldades e inquietações, eram discutidas pela equipe de participantes - então alunos da pós-graduação e da graduação.

À medida que se aproximava o final do mestrado, entretanto, ia se tornando premente uma inserção profissional mais regular, cujo detalhamento não é relevante para esse artigo, principalmente porque as faculdades particulares, mesmo que proporcionem experiências (em geral sofridas) de amadurecimento, quase sempre propiciam condições precárias de desenvolvimento acadêmico ${ }^{15}$.

Antes de ingressar no doutorado, um trabalho assinalável foi a co-organização de uma coletânea de textos na área das ciências sociais sobre os shopping centers no Brasil (Pintaudi; Frúgoli Jr., 1992) ${ }^{16}$, analisando realidades urbanas diferenciadas e representativas, através de distintos olhares - da antropologia, da geografia, da sociologia e do urbanismo. Isso resultou, em suma, num enfoque sobre os shoppings e fenômenos correlatos que buscou contribuir com pesquisas no campo das ciências humanas sobre o tema.

Como a área de estudos urbanos continuava a me suscitar grande interesse, concorri ao doutorado em Sociologia na USP, com um projeto inicialmente intitulado "Avenida Paulista: sociedade e cultura em São Paulo", sob a orientação de Maria Arminda do Nascimento Arruda, no qual pretendia analisar aspectos da dinâmica urbana e cultural da metrópole à luz de processos que se davam naquela avenida, cujo entorno vinha constituindo uma forte centralidade, com uma significativa densidade simbólica.

Nessa ocasião, fui convidado pela editora Marco Zero para escrever um livro ${ }^{17}$

\footnotetext{
${ }^{15}$ Após o final da graduação, tive a oportunidade de uma primeira experiência de docência no Ciclo Básico da PUC de São Paulo (na disciplina Problemas Filosóficos e Teológicos do Homem Contemporâneo), uma proposta então arrojada em termos pedagógicos, na qual todos os alunos, independentemente do curso, freqüentavam cinco disciplinas básicas, com ênfase numa formação inicial mais humanística, o que entretanto estava prestes a acabar, frente à demanda de várias faculdades por estabelecer de forma autônoma seus próprios ciclos introdutórios - o que veio a ocorrer em 1987. Posteriormente fui docente de sociologia na EAESP/Fundação Getúlio Vargas e integrei, naquela instituição, o Centro de Estudos da Cultura e do Consumo. Tornei-me também professor de antropologia da FCS/Fundação Cásper Líbero, onde ministrei aulas para alunos de jornalismo, publicidade e propaganda e relações públicas, do curso noturno, mais maduros que os do curso matutino, mas com a maioria extenuada pela jornada de trabalho.

${ }^{16}$ Silvana Pintaudi, geógrafa e professora da UNESP/Rio Claro, havia defendido uma tese de doutorado sobre os shoppings do interior do estado de São Paulo, e ambos sabíamos então de outros trabalhos recentes sobre o tema, o que nos levou a organizar tal livro.

${ }^{17}$ Que faria parte de uma coleção intitulada "Vida Cotidiana", projeto que depois não avançou dentro da editora, o que quase inviabilizou seu lançamento, que só ocorreu quando obtive por conta própria um patrocínio complementar do SESC-SP.
} 
que resultou no tratamento de questões relevantes acerca de espaços públicos de São Paulo à luz das interações sociais neles ocorridas, aproveitando que eu já realizara duas pesquisas sobre o tema ${ }^{18}$, procurando também fazer uma espécie de balanço de outros estudos no âmbito das ciências sociais — sobretudo aqueles que contivessem dados etnográficos reveladores de usos e ocupações sociais das ruas e espaços similares. Busquei assim avançar, refletindo sobre as mudanças mais abrangentes que vinham ocorrendo nos espaços públicos, marcadas por um certo abandono pelas camadas mais privilegiadas - concomitante a uma intensificação do seu uso pelas camadas populares para vários fins - enquanto que, simultaneamente, aumentavam espaços mais privatizados e seletivos, destinados sobretudo aos grupos de maior poder aquisitivo. Dessa forma, uma parte foi dedicada à área central de São Paulo - com certa deterioração dos equipamentos urbanos e uma ocupação diversificada de caráter mais popular - e outra abordou uma espécie de fragmentação dessa centralidade em espaços como shoppings, condomínios fechados, complexos empresariais e outros. Tal livro foi publicado em 1995, sob o título "São Paulo: espaços públicos e interação social” e penso que desempenhou seu papel numa sistematização antropológica concisa de várias etnografias sobre distintos usos dos espaços públicos da metrópole ${ }^{19}$.

Prosseguindo no doutorado, vinha enfrentando dificuldades para circunscrever mais precisamente o objeto de minha tese. Não havia então uma linha de pesquisa de estudos urbanos no Departamento de Sociologia com a qual pudesse dialogar melhor sobre minhas incertezas e apreensões, restando poucas oportunidades de interlocução ${ }^{20}$.

Esse conjunto de desafios convenceu-me da necessidade de uma reciclagem, tornada possível com uma "bolsa sanduíche" ${ }^{21}$, através do qual passei um ano (entre 1995 e 1996) como pesquisador visitante do Center for Iberian and Latin American Studies - CILAS, na University of California, San Diego - UCSD, sob a supervisão de James Holston, do Department of Anthropology da UCSD.

\footnotetext{
${ }^{18}$ As já mencionadas abordagens sobre o Largo da Concórdia e sobre os shopping centers.

${ }^{19}$ Apesar dos limites dessa publicação quanto a um debate teórico mais profundo, dado o espírito da demanda à qual inicialmente se destinava, como já dito. Parte das dinâmicas de uso dos espaços do centro de São Paulo foram também abordadas em “A guerra dos lugares” (Arantes, 2000, 105-129).

${ }^{20}$ Somava-se uma insatisfação quanto às limitações já descritas das atividades de docência que vinha desempenhando. Na EAESP/FGV, então meu principal local de trabalho, vinha lidando com classes cada vez mais indisciplinadas, cujos alunos incorporavam gradativamente o papel de "clientes", frente a professores vistos como "prestadores de serviços", com todo o tipo de prejuízos para o processo educacional propriamente dito.

${ }^{21}$ Obtida junto ao convênio CAPES-Fulbright.
} 
Além de um ambiente de trabalho acolhedor, as condições de pesquisa bibliográfica e de leituras foram muito boas, tendo entrado em contato com a literatura norte-americana sobre dinâmicas socioculturais das metrópoles contemporâneas, com forte tradição naquele país. Afora tal levantamento, pesquisei o material disponível em centros de pesquisa dali e de outras universidades, contatando em várias ocasiões professores e pesquisadores, ligados principalmente a outros centros de estudos latinoamericanos e brasileiros, bem como da área de estudos urbanos ${ }^{22}$.

Para além da experiência universitária propriamente dita, o fato de estar num outro país, com todas as descobertas e agruras decorrentes, propiciou-me um forte amadurecimento pessoal. Pude, ao longo de minha permanência, não somente vivenciar um cotidiano num contexto urbano muito distinto do Brasil, como também realizar por vezes pequenas viagens que ampliavam minha experiência como pesquisador e como citadino. Inevitável dizer que a experiência num contexto distinto propiciou-me um determinado estranhamento, a partir do qual pude avaliar melhor tanto a condição de estrangeiro quanto a de brasileiro, malgrado a complexidade desse tema.

San Diego, onde morei com minha família, é uma cidade bastante “suburbanizada" ${ }^{23}$, com regiões esparsas ligadas por auto-pistas, um modelo muito recorrente no sul da Califórnia. A experiência no trânsito dos Estados Unidos propiciou-me muitas comparações com o sistema brasileiro, à medida que há diferentes regras, maior rigor no cumprimento destas, e direitos mais efetivos atribuídos ao pedestre, apesar do primado do automóvel e de um sistema de transporte coletivo bastante escasso. As inúmeras atividades comunitárias e voluntárias desempenhadas ali e em outras cidades fizeram-me compreender melhor certos aspectos da cidadania norte-americana. San Diego ocupa uma posição geográfica peculiar, próxima à divisa com o México e com a cidade de Tijuana - que também visitei -, recebendo assim muitos imigrantes, a maior parte ilegais, que desempenham atividades informais e mal remuneradas. Configura-se ao longo de toda a fronteira entre Estados Unidos e México uma cultura fortemente marcada pelo hibridismo, alvo de muitos estudos ${ }^{24}$. Por outro

\footnotetext{
${ }^{22}$ Em algumas ocasiões apresentei pesquisas que já havia realizado, com comentários e sugestões animadores (agradecimentos especiais a Sharon Zukin).

${ }^{23}$ No sentido norte-americano do termo.

${ }^{24}$ Ver, a respeito, Herzog (1992) e Canclini (1997). Para uma abordagem antropológica mais recente e instigante a respeito, ver "Borders/Nodes/Groupings" (Herzfeld, 2006: 133-151).
} 
lado, sua posição no litoral do Pacífico tem ocasionado a vinda de muitos imigrantes orientais, que têm formado certos "nichos" (nas universidades e em alguns bairros).

Los Angeles, a duas horas dali, vem sendo considerada um importante paradigma de mudanças urbanas contemporâneas, cuja expressão propiciou o surgimento da "Los Angeles School" ${ }^{25}$, reunindo estudiosos ligados à temática urbana, com tópicos que incorporei seletivamente em minha tese de doutorado. Dada a proximidade com San Diego, foi igualmente alvo de especial atenção durante minhas visitas, principalmente no que diz respeito ao seu padrão acentuadamente descentralizado de urbanização, suas transformações no espaço público, seu modelo de segregação residencial, seu extenso sistema de auto-pistas, sua considerável diversidade étnica e sua indústria de lazer e cinema $^{26}$.

Dessa forma, foi possível aproveitar tal estadia no exterior como fonte de reflexão sobre a diversidade sociocultural. Ainda com relação aos Estados Unidos, retornei àquele país em 2001 e estava em Nova York quando ocorreram os atentados de 11 de setembro. Eu havia caminhado por aquela região um dia antes, mas naquela terçafeira estava no Queens, fora de Manhattan, quando se deram as explosões. Tal experiência inesperada e dramática permitiu-me ampliar de forma extraordinária meus conhecimentos sobre a realidade urbana nova-iorquina, que posteriormente elaborei no artigo "Nova York nos dias seguintes à tragédia" (nov./2001).

Voltando à bolsa-sanduíche, o principal avanço residiu na reformulação do objeto da pesquisa de doutorado, tendo basicamente chegado ao seguinte objetivo: analisar como a centralidade da cidade de São Paulo vinha sendo articulada, redefinida e negociada por grupos empresariais no período mais recente de sua vida urbana, comparando o contexto social de três espaços significativos, desenvolvidos ao longo do "quadrante sudoeste":

a) o Centro, que sofreu historicamente uma série de modificações, com a deterioração parcial de equipamentos urbanos e passando então por processos parciais de "revitalização" urbana, visto como espaço estratégico da vida metropolitana na ótica da Associação Viva o Centro;

b) a Avenida Paulista, uma espécie de desdobramento ampliado do centro tradicional sob a hegemonia do capital financeiro a partir da década de 1970,

\footnotetext{
${ }^{25}$ Ver, sobre tal escola, Dear (2000).

${ }^{26}$ Para um painel a respeito, ver Sorkin (1992).
} 
considerada a partir de 1990 o "símbolo da cidade", e cujo processo de deterioração urbana posterior levou à criação da Associação Paulista Viva;

c) a Avenida Eng. Luiz Carlos Berrini, representativa de uma tendência, a partir dos anos 1980, de concentração de multinacionais do setor terciário em São Paulo, com papel decisivo desempenhado pela empresa Bratke-Collet nessa estruturação, em cuja região se deu, em meados da década de 1990, a organização de um pool de empresários da região para a remoção de favelados de uma área das proximidades, durante a construção de uma avenida.

Os principais objetivos da tese estavam delineados, mas era necessário então preparar a volta ao Brasil. Mais difícil do que a ida, tal retorno impunha-me o contato com as antigas dificuldades, em que pese todo o salto de qualidade advindo da permanência no exterior. Uma das minhas intenções, concomitante à confecção da tese de doutorado, era buscar condições de trabalho acadêmico mais satisfatórias.

Ao final de 1997, participei de um concurso para lecionar antropologia para o Curso de Graduação em Ciências Sociais, no Departamento de Antropologia, Política e Filosofia da FCL/UNESP de Araraquara, em regime de dedicação integral, tendo obtido a vaga.

Tal inserção acarretou-me inestimáveis mudanças em minha trajetória. Passei a lecionar para alunos de Ciências Sociais, o que obviamente implicou num outro tipo de envolvimento com a matéria dada e com os debates em sala de aula. Isso me levou a um contato renovado com a bibliografia antropológica, tanto a clássica quanto a contemporânea. Comecei a orientar projetos de pesquisa de alunos da graduação, atividade que antes fizera apenas ocasionalmente, além de participar de bancas de monografia de orientandos de outros colegas do departamento e da faculdade, iniciando-me, após o doutorado, nas bancas de pós-graduação ${ }^{27}$. Com o tempo,

\footnotetext{
${ }^{27}$ Outro fato assinalável foi minha participação num módulo de um curso de pós-graduação lato-sensu oferecido pela UNESP, intitulado "Gestão Pública e Gerência de Cidades", para um público em geral ligado à administração pública de Araraquara, além de políticos profissionais, militantes, jornalistas etc. Uma das discussões empreendidas dizia respeito justamente ao processo de deterioração dos equipamentos urbanos do centro de São Paulo, com a formação, naquele caso, de uma associação de base empresarial visando reverter, com seus prós e contras, tal fenômeno. Eu havia sugerido uma discussão sobre Araraquara, apesar das consideráveis diferenças com relação à capital, e após vários pontos de vista, os alunos passaram a discutir um projeto polêmico em curso, do então prefeito, de remover os trilhos da Fepasa da área central da cidade, impermeabilizando a área e definindo novos usos, com altíssimos custos e resultados questionáveis, o que exigiria no mínimo um debate público mais aprofundado. Num momento em que Araraquara estava prestes a eleger um novo prefeito, um grupo da classe se empenhou no enfrentamento dessa e de outras questões urbanas candentes, formando posteriormente uma espécie de ONG, com uma composição bastante plural, chamada "Araraquara Viva",
} 
organizei informalmente um pequeno grupo de estudos de antropologia urbana com estudantes atraídos pelo tema, configurando-se um interesse que depois me levou a oferecer essa disciplina como optativa. Essa experiência permitiu-me não apenas retomar especificidades desta vertente da antropologia, como buscar compreender as particularidades socioculturais das cidades de médio porte em processo de metropolização - processo presente em algumas regiões do interior do estado de São Paulo -, cujos contextos evidentemente constituíam o interesse básico de pesquisa por parte dos estudantes ${ }^{28}$.

Passei também a escrever resenhas sobre livros acadêmicos para a grande imprensa ${ }^{29}$ e revistas universitárias. Tal atividade, além do desenvolvimento de um olhar mais crítico, advindo da responsabilidade de um posicionamento público quanto a obras acadêmicas, passou a propiciar o conhecimento de novos campos de produção, bem como um saber mais apurado sobre a própria maneira de se confeccionar um livro, expor os argumentos e defender os principais pontos de vista. Embora em muitos casos a pesquisa propriamente dita seja o substrato das obras acadêmicas, tenho a partir da presente atividade compreendido melhor a importância da construção textual propriamente dita.

Paralelamente, finalizei da tese de doutorado, defendendo-a em agosto de 1998. O retorno crítico de grande incentivo da banca, aliado às sugestões que obtive quando da apresentação de partes do trabalho em seminários e congressos levaram-me a preparar sua publicação, que se deu em meados de 2000 - intitulada "Centralidade em São Paulo: trajetórias, conflitos e negociações na metrópole”. A ressonância dessa pesquisa foi desde então bastante positiva, estabelecendo-se um diálogo com outras abordagens sobre o contexto urbano nas ciências sociais ${ }^{30}$.

voltada à qualidade de vida na cidade. A formação desse grupo, que pude acompanhar na própria sala de aula, possibilitou-me maior clareza quanto à potencialidade de uma das facetas da vida universitária, relativa às atividades de extensão.

${ }^{28}$ Outro aspecto que se tornara bastante visível é que a maioria das pesquisas e publicações da antropologia urbana abrangem principalmente as metrópoles (inicialmente os contextos carioca e paulista, tendo depois, evidentemente, se diversificado). Para uma abordagem que passa por tal discussão, ver Frúgoli Jr. (2008b).

${ }^{29}$ Com intensificação no período entre 1998 e 2001 (para o extinto "Caderno de Sábado" do Jornal da Tarde).

${ }^{30}$ Menciono aqui uma contribuição à antropologia urbana: “... num aglomerado contíguo com mais de dez milhões de habitantes, como é o caso da cidade de São Paulo, não há uma, mas várias centralidades (Frúgoli, 2000) e, em vez de se procurar (em vão) um princípio de ordem que garanta a dinâmica da cidade como um todo, mais acertado é tentar identificar essas diferentes centralidades e os múltiplos ordenamentos que nelas e a partir delas ocorrem" (Magnani, 2002: 15). 
A partir dessa época, começaram a surgir convites para investigações de curto prazo, com a possibilidade da retomada renovada de alguns enfoques, ou de incursões por novos terrenos. Ainda em 2000, realizei uma breve etnografia de dois centros comerciais tradicionais e dois shopping centers da Zona Leste de São Paulo ${ }^{31}$. Foi interessante observar, no caso do Shopping Aricanduva, situado em meio a uma enorme área de habitações precárias, o aprofundamento da absorção de camadas populares (já constatada uma década antes no caso do Shopping Center Norte), então em curso numa nova fronteira de expansão do comércio varejista moderno. Isso resultou, em 2001, na produção de um texto (em parceria com Raquel Rolnik, coordenadora do projeto), sobre as especificidades da espacialização da desigualdade nessa extensa área urbana de São Paulo ${ }^{32}$.

Um ano depois, tive a rara oportunidade de fazer outra breve pesquisa de campo na pequena cidade de Beuningen, na Holanda ${ }^{33}$. Tal região havia experimentado uma primeira fase de expansão há vinte anos, com a construção de casas em massa pelo Estado, atraindo uma parcela da população da cidade vizinha de Nijmegen, que passou a conviver com os fazendeiros locais. Mais recentemente, entretanto, ocorrera uma nova expansão imobiliária, com a produção de moradias mais caras, trazendo dessa vez parte da classe média alta que trabalha em Nijmegen, mas que prefere morar fora da cidade, à busca de contato com a paisagem rural circundante e da prática da recreação. Trata-se de um processo de suburbanização, que se desenvolve com facetas particulares naquele país ${ }^{34}$ e que configura, no caso de Beuningen - numa fase peculiar de transição do rural para o urbano - uma crescente diversificação de grupos sociais, mais nítida sobretudo através do contraste, por vezes conflitivo, entre os antigos e os novos residentes. Enfoquei tal contexto numa ótica antropológica, centrando a análise numa retomada crítica do conceito de comunidade - sua dissolução e suas tentativas de reinvenção (já que bastante acionada pelos sujeitos na ocasião) -, buscando discutir alguns dos significados que essa noção suscitava naquele caso (Frúgoli Jr., 2003).

\footnotetext{
31 Esses últimos com perfis bastante distintos em termos socioculturais, numa consultoria para uma pesquisa mais abrangente sobre essa região, num convênio entre a PUC de Campinas e o Instituto Pólis.

32 Recentemente retomei tal temática quando da então possível construção de um estádio em Itaquera (Zona Leste de São Paulo) para a próxima Copa do Mundo (Frúgoli Jr., 14/11/2010).

${ }^{33}$ Numa consultoria para a Fundação Van Weurt tot Deest e o Bureau Venhuizen, que desenvolviam um projeto de intervenção no local.

${ }^{34}$ Ver, a respeito, Boeijenga and Mensink (2008).
} 
Por uma conjunção de fatores, foi possível retornar à Holanda outras vezes ${ }^{35}$, repetindo-se, gradativamente, um conhecimento um pouco mais aprofundado sobre outro país. Na última vez (2010), tive a chance de uma experiência como professor visitante na Cátedra de Estudos Brasileiros na Universidade de Leiden, onde ministrei dois cursos de antropologia da cidade, um sobre o Rio de Janeiro e outro sobre São Paulo, com novos aprofundamentos a respeito das respectivas produções relativas a ambos os contextos ${ }^{36}$. Tendo morado por alguns meses em Leiden, foi possível incluir (gradativamente, e quando diminuiu a neve...) o uso da bicicleta no cotidiano, meio de transporte, como se sabe, altamente utilizado no país, com forte influência numa série de usos dos espaços (tanto da cidade como do campo), e que hoje em dia inspira uma série de movimentos por novas formas de utilização das cidades.

Outra experiência de pesquisa, um pouco mais aprofundada, ocorreu em São Bento do Sapucaí (SP). A primeira, decorrente de uma atividade inicialmente de consultoria para a confecção de um Plano Diretor para a cidade ${ }^{37}$, com uma investigação centrada nos grupos políticos assinalados por significativas matrizes discursivas e uma agenda de desenvolvimento local monopolizada por moradores recentes (ou "de fora") (Frúgoli Jr., 2006). No período posterior, a partir de pistas etnográficas, desenvolveu-se uma pesquisa mais detida com grupos locais, situados em bairros rurais, com práticas e representações distintas dos anteriores - em termos territorial, parental, religioso e político. Sem pretender delimitar uma rígida separação entre cidade e campo, há muito criticada, foi instigante contrapor essas duas experiências, com ênfase nos modos diferenciados através dos quais esses grupos constroem suas representações, com ênfase, no último caso, na "política de santo" (Frúgoli Jr. e Spaggiari, 2009).

Principalmente a partir de 2003, ano de meu ingresso como docente no Departamento de Antropologia da USP, pode-se falar numa multiplicação e simultaneidade de experiências acadêmicas, tornando-se necessário um enfoque seletivo

\footnotetext{
${ }^{35}$ Em maio de 2002, tive a oportunidade de participar do seminário "Urban transformation and social reconstruction in Brazil", na Universidade de Utrecht, organizada pelo antropólogo brasilianista Geert Banck, quando de sua aposentadoria. Outras idas decorreram de diálogos profícuos com o arquiteto e urbanista Paul Meurs. Em 2009 participei de um programa de visitas internacionais promovido pelo Estado holandês, com o conhecimento pontual de realidades culturais e paisagens urbanas bastante variadas.

${ }^{36}$ Experiência muito estimulante, na qual um dos desafios foi dialogar, do ponto de vista antropológico, com as interrogações dos alunos, a maioria delas advindas de um olhar sobre a América Latina e o Brasil.

${ }^{37}$ Ligado à Oficina Municipal (articulada à Fundação Konrad Adenauer), em parceria com a prefeitura daquele município.
} 
quanto aos aspectos assinaláveis ao presente artigo. Dois anos depois, ao contar com um pequeno porém sólido número de orientandos, criei um novo grupo de estudos, que veio a se chamar GEAC (Grupo de Estudos de Antropologia da Cidade), para encontros regulares voltados ao debate e à reflexão sobre temas ligados à teoria e à pesquisa nesse campo antropológico, do qual ocasionalmente participavam pós-graduandos e estudantes sob outras orientações. Tal experiência contou com o engajamento efetivo dos estudantes, com a formação de um campo de trocas assinalado por um forte coleguismo. Numa primeira etapa, pode-se dizer que as leituras e discussões situavamse num contraponto entre abordagens antropológicas e sociológicas sobre a cidade, tendo como uma intersecção, produtora de um tensionamento benéfico, a prática etnográfica (Frúgoli Jr., 2005). Aos poucos, passamos a estudar e confrontar vertentes distintas no interior da própria antropologia, e a experiência até então instigou-me a escrever um pequeno livro - "Sociabilidade urbana" (2007) ${ }^{38}$ - no qual basicamente busquei traçar a genealogia de conceitos referenciais na antropologia da cidade, sobretudo sociabilidade e situação, além da abordagem sobre contrapontos entre as figuras do citadino e do cidadão, explorando o caráter relacional das modalidades de interação criadas e dissolvidas na cidade ${ }^{39}$. Dessa forma, foi possível retomar de um ponto de vista teórico algumas de minhas experiências de pesquisa anteriores, bem como articular um campo parcial de referências transversais entre os participantes daqueles debates ${ }^{40}$.

Sem pretender cobrir todas as orientações já realizadas ${ }^{41}$, pode-se dizer que a partir do ingresso na USP foi possível acompanhar pesquisas que de certa forma passaram a se aproximar bem mais (em distintos graus) de temas ligados à antropologia da cidade, assim como se beneficiaram de questões tratadas em nossos debates. Atendome aqui apenas ao campo da pós-graduação, pode-se mencionar os trabalhos

\footnotetext{
${ }^{38}$ A convite de Celso Castro, diretor da coleção da qual fez parte a publicação.

${ }^{39}$ Além de uma retomada crítica de estudos das Escolas de Chicago e de Manchester.

40 Mesmo reconhecendo, evidentemente, que cada orientando incorporou de forma seletiva tais referências, tendo em vista os desafios e metas estabelecidos nas respectivas pesquisas (naquele período, dissertações de mestrado e pesquisas de iniciação científica).

${ }^{41}$ Não citarei dissertações de ex-orientandos da pós-graduação na UNESP-Araraquara, cujas pesquisas extrapolavam o campo da antropologia da cidade - com exceção da tese de doutorado de Fernanda T. Márques sobre prostituição masculina na área portuária de Santos (2002), na qual fui co-orientador -, nem as orientações de iniciação científica (na USP e UNESP) ou acompanhamentos de monografias de fim de graduação na UNESP, algumas das quais renderam depois boas investigações de pós-graduação, sob outras orientações.
} 
etnográficos ${ }^{42}$ de Jessica Sklair (2010), com enfoque em articulações entre filantropia e segregação ${ }^{43}$, de Daniel D. L. R. Costa (2007), a respeito de múltiplos agenciamentos em torno da população de rua, de Carlos F. de Aquino (2008) e Inácio de C. D. de Andrade (2010), sobre práticas e representações de movimentos de luta por moradia (o primeiro sobre grupos atuantes no centro de São Paulo, e o segundo voltado a acampamento periférico em São José dos Campos, SP) e de Enrico Spaggiari (2009) ${ }^{44}$, sobre redes situadas no cruzamento entre interações citadinas e aprendizado da prática futebolística ${ }^{45}$.

Penso que outra contribuição substancial que se iniciou na década passada foi o fortalecimento do campo de debates sobre antropologia urbana (bem como sobre os estudos urbanos nas ciências sociais), ao coordenar (sempre de forma partilhada) grupos de trabalho em vários fóruns acadêmicos.

O primeiro ocorreu num Congresso da Brazilian Studies Association - BRASA (Recife, 2000) - quando coordenei uma mesa ${ }^{46}$ reunindo pesquisadores de outras cidades brasileiras para discutir, no campo das ciências sociais, questões relevantes a respeito dos conflitos ligados a processos de revitalização em áreas centrais. Revelou-se então um campo promissor de questões, sobretudo pelo desafio da diversidade de experiências em curso e pela necessidade de avaliar o alcance de conceitos - gerados no contraponto entre a análise de processos europeus ou norte-americanos e brasileiros.

O passo seguinte foi uma parceria estabelecida com Fernanda Peixoto, quando ministramos conjuntamente, em 2001, o curso "Tópicos especiais em teoria sociológica: sociabilidade urbana e pensamento social" junto ao Programa de Pós-Graduação em

\footnotetext{
${ }^{42}$ Todos de mestrado e com foco majoritário em São Paulo.

${ }^{43}$ Cuja dissertação foi defendida em 2007 (considerada a melhor dissertação daquele ano do PPGAS/USP, tendo participado do concurso anual de melhores dissertações e teses brasileiras da ANPOCS) e o livro publicado três anos depois.

${ }^{44}$ Indicada em 2011 para publicação (eletrônica) na Série Produção Acadêmica Premiada da FFLCH/USP; atualmente o mesmo investiga redes ligadas à formação de jogadores de futebol (doutorado).

${ }^{45} \mathrm{Em}$ andamento, pode-se mencionar pesquisas sobre o contexto paulistano - a de Guilhermo A. Aderaldo, a respeito das redes envolvidas na produção audiovisual sobre periferia (doutorado), a de Giancarlo M. C. Machado, sobre interações entre skatistas em diversas situações urbanas (mestrado), a de Bianca B. Chizzolini, sobre redes de relações entre moradores, comerciantes e proprietários do Centro (mestrado) -, além de investigações no Rio de Janeiro - a de Juliana B. Cunha, sobre processos de intervenção no complexo Pavão-Pavãozinho-Cantagalo (doutorado), a de Natália H. Fazzioni, a respeito de territorialidades do bairro da Lapa (mestrado), a de Mayã M. Correia, sobre conflitos ligados a intervenções na região portuária (mestrado) -, em Fortaleza - de Marina R. de O. Saraiva, sobre experiências citadinas de crianças (doutorado) - e na aldeia portuguesa de Vilas Boas - de Weslei E. Rodrigues, sobre processos de emigração e retorno (mestrado).

${ }^{46}$ Apenas nesse caso fui o único coordenador.
} 
Sociologia da FCL/UNESP/Araraquara ${ }^{47}$. Com base em nossas distintas trajetórias intelectuais, procuramos explorar determinadas polaridades presentes em vários estudos voltados à interpretação do contexto urbano, tais como rural e urbano, comunidade e sociedade, público e privado, tradicional e moderno, casa e rua, entre outras, buscando avaliar a vitalidade e escopo desses e de outros possíveis recortes ou tipologias analíticas.

Posteriormente isso se materializou num fórum de pesquisa, por nós coordenado na 23a Reunião Brasileira de Antropologia da ABA (Gramado, 2002) - "Cidades, representações e experiência social" - cujas sessões denominavam-se respectivamente "as cidades" (em que as mesmas aparecem como o tema geral da reflexão), "nas cidades" (onde são sobretudo cenário de experiências variadas) e "sobre as cidades" (em que são tomadas como matéria de discursos e representações). Os diálogos estabelecidos a partir dessas perspectivas foram positivos, reafirmando-se a vitalidade dos estudos urbanos na área da antropologia, desde que atentos a uma reflexão crítica e consequente sobre impasses e desafios.

\footnotetext{
${ }^{47}$ Nessa época éramos colegas na UNESP, e hoje Fernanda também é professora do Departamento de Antropologia da USP.
} 


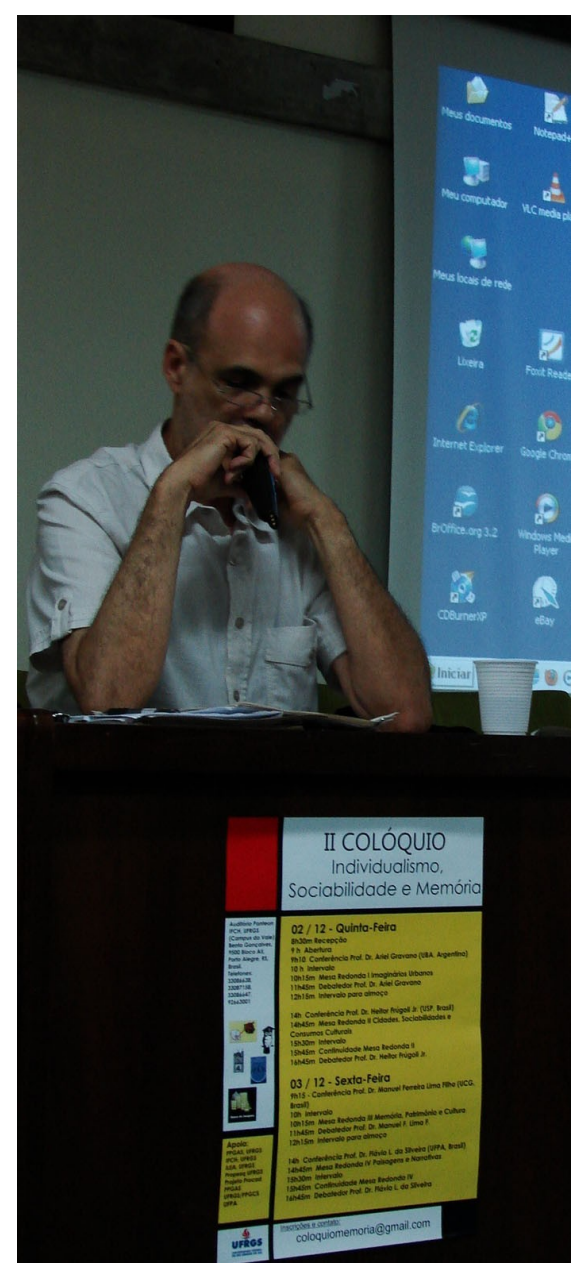

Heitor Frúgoli Jr. Foto de 02 dezembro 2010. II Colóquio Individualismo, Sociabilidade e Memória. Acervo BIEV PPGAS IFCH UFRGS.

Tal experiência foi retomada na RBA seguinte (Olinda, 2004), em parceria com Luciana Teixeira de Andrade, no fórum "As múltiplas faces da cidade do urbano", cuja densidade obtida levou-nos a produzir a coletânea "As cidades e seus agentes: práticas e representações" (Frúgoli Jr; Andrade; Peixoto, 2006), reunindo (de forma panorâmica, mas articulada) trabalhos apresentados nos fóruns de 2002 e 2004, alinhavados em três partes: intervenções urbanas e patrimônio; imaginário, história e memória; segregação espacial e dinâmicas culturais ${ }^{48}$.

O desafio seguinte foi a articulação de um grupo de trabalho na ANPOCS (20072009), em parceria com Laura Graziela Gomes - “A cidade nas ciências sociais: teoria, pesquisa e contexto" ${ }^{49}$ - com o apoio de vários daqueles que haviam participado da ${ }^{48}$ Houve ainda um desdobramento dessa experiência na RBA seguinte (Goiânia, 2006), com um GT coordenado por Fraya Frehse e Rogério Proença Leite.

${ }^{49}$ Ocorrido entre 2008 e 2009, e antecedido pelo ST "Cidades; perspectivas e interlocuções nas ciências sociais" (2007). 
experiência anteriormente mencionada. Apesar de passarmos de um campo predominantemente antropológico (RBA) para um campo mais voltado a interlocuções nas ciências sociais (ANPOCS), procuramos definir eixos mais precisos, voltados prioritariamente a reflexões sobre a prática etnográfica urbana (e sua influência principalmente nas abordagens da antropologia e sociologia urbanas), além da busca, simultânea, da compreensão de fenômenos significativos em curso nas cidades e da explicitação das perspectivas de análise sobre o urbano. Tal experiência resultou no dossiê "Cidade, teoria, etnografia" (Frúgoli Jr; Gomes, 2010), com a divulgação de trabalhos expressivos, bem como na sua consolidação e continuidade na ANPOCS ${ }^{50}$.

Penso com isso ter contribuído na consolidação desse campo de estudos, sobretudo na área de antropologia, cujos desdobramentos - diretamente ligados a tais experiências ou já articulados por outras composições - considero bastante promissores.

As pesquisas mais recentes e ainda em andamento, que envolvem outros contextos em São Paulo e uma frente de investigação em Lisboa ${ }^{51}$ - com um novo arco de relações acadêmicas e uma série de desafios instigantes - ficarão para outro artigo, até porque ainda exigem uma reflexão mais detalhada e aprofundada quanto aos achados e constatações. A única exceção fica para a menção, quase ao final desse texto, à minha participação, na revisão conceitual ${ }^{52}$ e na co-escrita (Cordeiro; Frúgoli Jr., 2011) do prefácio à edição brasileira do livro “Antropologia da cidade” (Agier, 2011), traduzido pela antropóloga portuguesa Graça Índias Cordeiro, com quem já tivera a oportunidade de coordenar, em parceira, o painel temático "A cidade e o urbano em questão: contextos, intersecções, diálogos" (Lisboa, 2009, IV Congresso da Associação Portuguesa de Antropologia) $)^{53}$. Por ocasião do lançamento desse livro em Lisboa (2011), Graça e eu co-organizamos um debate - "Antropologia da cidade em língua portuguesa" - cuja participação do autor e de antropólogos e cientistas sociais portugueses e brasileiros permitiu um diálogo profícuo.

Ao final do relato dessa trajetória, marcada por várias tentativas de desvelamento da cidade a partir de pesquisas, situadas em certo trânsito disciplinar (hoje

\footnotetext{
${ }^{50}$ Em ST e GT em andamento, sob a coordenação de Cristina Patriota de Moura e Mariana Cavalcanti.

${ }^{51}$ A partir de 2006, ano de meu ingresso na Rede Brasil-Portugal de Estudos Urbanos.

${ }^{52}$ Em parceria com José Guilherme Magnani.

${ }^{53}$ Em 2005, tinha tido minha primeira experiência internacional, na coordenação (em parceria com a antropóloga argentina Mónica Lacarrieu) do simpósio "Ciudad y ciudades: nuevas estrategias de lugares entre políticas de la cultura, políticas sociales y procesos de apropiación socio-cultural en las urbes latinoamericanas" (Rosário, 2005, Asociación Latinoamericana de Antropología).
} 
bem mais difícil de ser realizado) que culminou numa opção claramente antropológica (mesmo quando da incursão pela sociologia, a cidade continuou a ser alvo de um enfoque privilegiado), é possível assinalar breves aspectos transversais - sem buscar esgotá-los.

Uma primeira observação diz respeito aos vários significados atribuídos à cidade de São Paulo ao longo da minha própria trajetória de vida, tendo nascido e vivido na mesma, mas posteriormente mudado dali, o que fez com que meu retorno adviesse basicamente de dois projetos, em momentos (e com alcances) distintos, porém ambos ligados à universidade: o primeiro como estudante de ciências sociais, o segundo já como professor (ambos na USP). Tais afastamentos e aproximações de certa forma auxiliaram-me a aprender a olhar (e assim apreender) tal cidade (e suas múltiplas espacialidades) sob óticas diferenciadas (de "longe", de "perto", de "dentro"...), e com isso, atentar bastante às representações a respeito acionadas pelos sujeitos e interlocutores pesquisados, embora nesses casos a responsabilidade para evitar um viés etnocêntrico seja ainda maior.

De toda forma, também tem sido possível vivenciar experiências de pesquisa (ou mesmo pessoais) em contextos marcados por maior estranhamento - por mais que essa categoria suscite tantas relativizações -, o que espero ter ficado claro à medida que alinhavei abordagens de longo prazo com outras de menor escopo e enfoque mais concentrado ${ }^{54}$.

\footnotetext{
${ }^{54}$ Uma experiência etnográfica de mais longo prazo, recentemente passada em Lisboa, abre um novo campo de reflexões, mas que ficarão, como já dito, para outros escritos.
} 


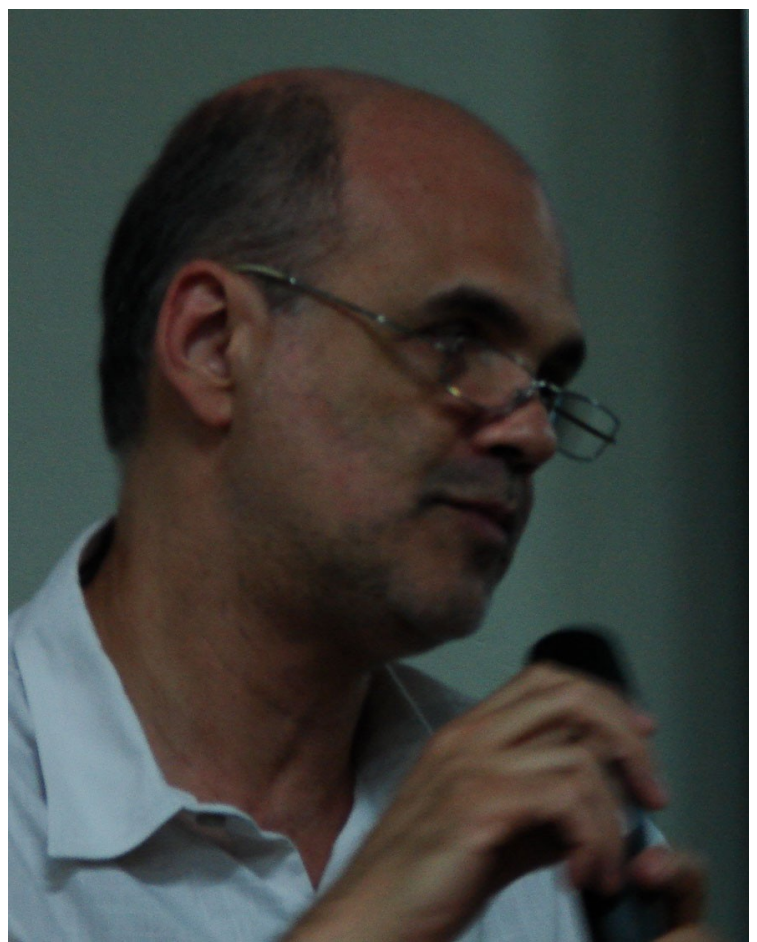

Heitor Frúgoli Jr. Foto de 02 dezembro 2010. II Colóquio Individualismo, Sociabilidade e Memória. Acervo BIEV PPGAS IFCH UFRGS.

$* * *$

Tudo o que foi tratado aqui denota uma trajetória voltada a uma antropologia da cidade, em que a mesma: é objeto privilegiado de reflexão, e não apenas pano de fundo de experiências; envolve uma problematização constante das especificidades das redes de relações criadas em tais contextos - nas quais o conceito de sociabilidade e suas derivações têm importante papel; possui como tema transversal a articulação dos atores sociais com o espaço e os equipamentos urbanos; exige uma atenção especial ao modo como se apreende a alteridade - nos jogos entre "familiaridade e estranhamento", "at home" (em casa), "de nós mesmos", "alteridade próxima" etc ${ }^{55}$.

A etnografia tem sido, dessa forma, uma referência fundamental cujas sendas pretendo continuar explorando - e até quando possível, como etnógrafo - dentro da busca incessante dos significados da cidade e do urbano na antropologia.

\footnotetext{
${ }^{55}$ Ver a respeito Velho (1978), Durham (2004 [1986]), Magnani (2002), Peirano (2006: 37-67), Frúgoli Jr. (2007).
} 


\section{Referências}

AGIER, M. Antropologia da cidade: lugares, situações, movimentos. São Paulo: Terceiro Nome, 2011.

ANDRADE, I. de C. D. de. Movimento social, cotidiano e política: uma etnografia da questão identitária dos sem-teto. Dissertação de mestrado. São Paulo: PPGAS/USP, 2010.

ANDRADE, L. T. de. A Belo Horizonte dos modernistas: representações ambivalentes da cidade moderna. Belo Horizonte: Ed. PUC Minas, 2004.

AQUINO, C. R. F. de. A coletivização como processo de construção de um movimento de moradia: uma etnografia do Movimento Sem-Teto do Centro (MTSC). Dissertação de mestrado. São Paulo: PPGAS/USP, 2008.

ARANTES, A. A. Paisagens paulistanas: transformações do espaço público.. Campinas: Ed. Unicamp, 2000.

ARRUDA, M. A. do N. Metrópole e cultura: São Paulo no meio século XX. Bauru: Edusc, 2001.

BANCK, G. "Memórias e tradições. Cultura política: Brasil versus Holanda". In: Revista Brasileira de Ciências Sociais nº 65, vol. 22, São Paulo: ANPOCS, out./ 2007, p. 127-138.

BLAY, E. (org.). A luta pelo espaço: textos de sociologia urbana. São Paulo: Vozes, $1979,2^{\mathrm{a}}$ ed.

BOEIJENGA, J. \& MENSINK, J. Vinex Atlas. Rotterdam: Uitgeverij 010 Publishers, 2008.

BOURDIEU, P. Esboço de auto-análise. São Paulo: Cia. das Letras, 2005.

CALDEIRA, T. P. R. A. A cidade de muros: crime, segregação e cidadania em São Paulo. São Paulo: Edusp/Ed. 34, 2000.

CANCLINI, N. Culturas hibridas: estratégias para entrar e sair da modernidade. São Paulo: Edusp, 1997.

CARDOSO, R. (org.). A aventura antropológica: teoria e pesquisa. Rio de Janeiro: Paz e Terra, 1986.

CORDEIRO, G. Í. e FRÚGOLI JR., H. "Prefácio à edição brasileira". In: AGIER, M. Antropologia da cidade: lugares, situações, movimentos. São Paulo: Terceiro Nome, 2011. p. 9-29.

COSTA, D. de L. R. A rua em movimento: experiências urbanas e jogos sociais em torno da população de rua. Dissertação de mestrado. São Paulo: PPGAS/USP, 2007.

DEAR, M. J. The postmodern urban condition. Oxford/Malden: Blackwell Publishers, 2000.

DOUGLAS, M. e ISHERWOOD, B. O mundo dos bens: para uma antropologia do consumo. Rio de Janeiro: Ed. UFRJ, 2004 [1979].

DURHAM, E. R. "A pesquisa antropológica com populações urbanas". In: DURHAM, E. R. A dinâmica da cultura. São Paulo: Cosac \& Naify, 2004 [1986]. p. 357-376.

ELIAS, E. e SCOTSON, J. L. Os estabelecidos e os outsiders: sociologia das relações de poder a partir de uma pequena comunidade. Rio de Janeiro: Jorge Zahar, 2000.

FIX, M. Parceiros da exclusão: duas histórias de uma "nova cidade" em São Paulo: Faria Lima e Água Espraiada. São Paulo: Boitempo, 2001.

FRÚGOLI JR., H. “A arena em torno do futuro Plano Diretor de São Bento do Sapucaí (SP): novos significados da relação entre cidade e campo". In: FRÚGOLI JR., H.; 
ANDRADE, L. T. de; PEIXOTO, F. A. (orgs.). As cidades e seus agentes: práticas e representações. Belo Horizonte: Ed. PUC Minas/Edusp, 2006. p. 277-304.

FRÚGOLI JR., H. "A dissolução e a reinvenção do sentido de comunidade em Beuningen, Holanda". In: Revista Brasileira de Ciências Sociais, vol. 18, no 52, fev./2003. São Paulo: ANPOCS, 2003. p. 109-126.

FRÚGOLI JR., H. "Distinção entre centro e periferia fica mais turva". In: Folha de São Paulo, 14/11/2010. São Paulo: Revista São Paulo. p. 27.

FRÚGOLI JR., H. "Nexos simbólicos entre capital e interior paulista: reinterpretações recentes da cultura caipira". In: SETUBAL, M. A. e MARINS, P. C. G. (orgs). Terra Paulista: trajetórias contemporâneas. São Paulo: CENPEC/Imprensa Oficial do Estado de São Paulo, 2008b. p. 169-186.

FRÚGOLI JR., H. "Nova York nos dias seguintes à tragédia (editorial)". In: Portal de Arquitetura e Urbanismo Vitruvius, nov./2001. São Paulo: Vitruvius. Disponível em: http://www.vitruvius.com.br/revistas/read/arquitextos/02.018/826

FRÚGOLI JR., H. "O urbano em questão na antropologia: interfaces com a sociologia". In: Revista de Antropologia vol. 48, $\mathrm{n}^{\mathrm{o}}$ 1. São Paulo: Departamento de Antropologia/USP, 2005. p. 107-124.

FRÚGOLI JR., H. "Os shoppings de São Paulo e a trama do urbano: um olhar antropológico". In: PINTAUDI, S. M. e FRÚGOLI JR., H. (orgs.). Shopping Centers: espaço, cultura e modernidade nas cidades brasileiras. São Paulo: Ed. Unesp, 1992. p. 75-92.

FRÚGOLI JR., H. "Sociabilidade e consumo nos shopping centers de São Paulo: eventos e desafios recentes". In: BUENO, M. L. e CAMARGO, L. O. de L. (orgs.). Cultura e consumo: estilos de vida na contemporaneidade. São Paulo: Senac São Paulo, 2008a. p. 231-246.

FRÚGOLI JR., H. Centralidade em São Paulo: trajetórias, conflitos e negociações na metrópole. São Paulo: Cortez/Edusp/Fapesp, 2000.

FRÚGOLI JR., H. São Paulo: espaços públicos e interação social. São Paulo: Marco Zero, 1995.

FRÚGOLI JR., H. Sociabilidade urbana. Rio de Janeiro: Jorge Zahar, 2007.

FRÚGOLI JR., H. e GOMES, L. G. "Dossiê: cidade, teoria, etnografia". In: Antropolítica $\mathrm{n}^{\mathrm{o}}$ 28, vol. 1. Niterói: EdUFF, 2010. p. 11-18. Disponível em: http://www.revistas.uff.br/index.php/antropolitica/article/view/19/pdf

FRÚGOLI JR., H. e SPAGGIARI, E. "A 'política de santo' no bairro rural do Baú do Centro". In: Revista de Antropologia vol. 52, $\mathrm{n}^{\circ}$ 2. São Paulo: Departamento de Antropologia/USP, 2009. p. 533-569.

FRÚGOLI JR., H.; ANDRADE, L. T. de; PEIXOTO, F. A. (orgs.). As cidades e seus agentes: práticas e representações. Belo Horizonte: Ed. PUC Minas/Edusp, 2006.

GOMES, L. G. "La Maison des Métallos: representações e estratégias de preservação do patrimônio no leste parisiense". In: FRÚGOLI Jr., H.; ANDRADE, L. T. de; PEIXOTO, F. A. (orgs.). As cidades e seus agentes: práticas e representações. Belo Horizonte: Ed. PUC Minas/Edusp, 2006. p. 128-149.

HANNERZ, U. Exploring the city: inquiries toward an Urban Anthropology. New York: Columbia University Press, 1980.

HERZFELD, M. Anthropology: theoretical practice in culture and society, $6^{\text {th }}$ ed. Malden/Oxford/Carlton: Blackwell Publishers, 2006. 
HERZOG, L. (ed.). Changing boundaries in the Americas: new perspectives on the $U$. S.-Mexican, Central American, and South American borders. San Diego: Center for U. S.-Mexican Studies, UCSD, 1992.

HOLSTON, J. A cidade modernista: uma crítica de Brasília e sua utopia. São Paulo: Cia. das Letras, 1993.

JOSEPH, I. L'athléte moral et l'enquêteur modeste. Paris: Economica, 2007.

KOWARICK, L. Escritos urbanos. São Paulo: Ed. 34, 2000.

LACARRIEU, M. B.; CARMAN, M.; GIROLA, M. F. "Procesos de transformación urbana en lugares centrales y periféricos del área metropolitana de Buenos Aires: ganó el urbanismo escenográfico?”. In: FRÚGOLI JR., H.; ANDRADE, L. T. de; PEIXOTO, F. A. (orgs.). As cidades e seus agentes: práticas e representações. Belo Horizonte: Ed. PUC Minas/Edusp, 2006. p. 98-127.

MACEDO, M. "Baladas black e rodas de samba da terra da garoa". In: MAGNANI, J. G. C. e SOUZA, B. M. (orgs.). Jovens na metrópole: etnografias de circuitos de lazer, encontro e sociabilidade. São Paulo: Terceiro Nome, 2007. p. 189-224.

MÁRQUES, F. T. No cais do porto: um estudo etnográfico da prostituição viril na região portuária santista. Tese de doutorado. Araraquara: PPGS/UNESP, 2002.

MAGNANI, J. G. C. "De perto e de dentro: notas para uma etnografia urbana". In: Revista Brasileira de Ciências Sociais, n ${ }^{\circ}$ 4, vol. 17, jun./ 2002. São Paulo: ANPOCS. p. 11-29.

PEIRANO, M. A teoria vivida e outros ensaios de antropologia. Rio de Janeiro: Jorge Zahar, 2006.

PEIXOTO, F. A. "As cidades nas narrativas sobre o Brasil". In: FRÚGOLI JR., H.; ANDRADE, L. T. de; PEIXOTO, F. A. (orgs.). As cidades e seus agentes: práticas e representações. Belo Horizonte: Ed. PUC Minas/Edusp, 2006. p. 177-197.

PINTAUDI, S. M. e FRÚGOLI JR., H (orgs.). Shopping Centers: espaço, cultura e modernidade nas cidades brasileiras. São Paulo: Ed. Unesp, 1992.

PUCCINELLI, B. "Territórios sexuais: análise de sociabilidades homossexuais no shopping gay de São Paulo". Revista Latino-Americana de Geografia e Gênero, v. 2, n. 1, jan.-jul./2011,. Ponta Grossa: UEPG. p. 133-140.

ROLNIK, R. e FRÚGOLI JR., H. "Reestruturação urbana da metrópole paulistana: a Zona Leste como território de rupturas e permanências". In: Cadernos Metrópole, no 6. São Paulo: Educ, 2001. p. 55-83.

SIMMEL, G. "Sociability". In: LEVINE, D. N. (ed.). Simmel: on individuality and social forms. Chicago/London: Chicago University Press, 1971 [1917]. p. 127-140.

SKLAIR, J. A filantropia paulistana: ações sociais em uma cidade segregada. São Paulo: Humanitas, 2010.

SORKIN, M. (ed.). Variations on a theme park: the new American city and the end of public space. New York: Hill and Wang, 1992.

SPAGGIARI, E. Tem que ter categoria: construção do saber futebolístico. Dissertação de mestrado. São Paulo: PPGAS/USP, 2009.

TURNER, V. Dramas, campos e metáforas: ação simbólica na sociedade humana. Niterói: EdUFF, 2008 [1974].

VELHO, G. "Observando o familiar". In: NUNES, E. (org.). A aventura sociológica. Rio de Janeiro: Jorge Zahar, 1978. p. 36-46.

ZUKIN, S. The cultures of cities. Cambridge/Oxford: Blackwell Publishers, 1995. 